\title{
Effect of $N$-acetyl cysteine on the concentrations of thiols in plasma, bronchoalveolar lavage fluid, and lung tissue
}

Myrtle M E Bridgeman, Mark Marsden, Colin Selby, Douglas Morrison, William MacNee

\begin{abstract}
Background - Oxidant/antioxidant imbalance may occur in the lungs of patients with chronic obstructive pulmonary disease (COPD). Glutathione is an important extracellular and intracellular thiol oxidant in the lungs. These studies were carried out to determine the effect of $\mathbf{N}$-acetyl cysteine on thiol concentrations in plasma, bronchoalveolar lavage fluid, and lung tissue.

Methods - Studies were carried out on normal subjects, patients with COPD, and those undergoing lung resection. In the first study $\mathbf{N}$-acetyl cysteine was given to three groups; healthy subjects (600 mg once daily by mouth) and two groups of patients with COPD. In the first group of patients with COPD the dose was $600 \mathrm{mg}$ once daily and in the second $600 \mathrm{mg}$ thrice daily, all for five days. The latter dosage regimen was also given to six patients before bronchoscopy and to 11 patients before lung resection. Lung glutathione (GSH) levels in bronchoalveolar lavage fluid or lung tissue were compared with the same numbers of patients who did not receive $\boldsymbol{N}$-acetyl cysteine.
\end{abstract}

Results - $\mathbf{N}$-acetyl cysteine was detected in plasma after a single $600 \mathrm{mg}$ dose in normal subjects and patients with COPD up to 1.5 hours after the drug was given. Plasma cysteine concentrations increased in normal subjects on both days 1 and 5 , and in patients with COPD on day 5. Glutathione concentrations in plasma increased on day 1 in normal subjects but not in patients with COPD given $600 \mathrm{mg} N$-acetyl cysteine daily. With the higher dose of $600 \mathrm{mg}$ thrice daily, however, there was a sustained elevation of GSH concentrations in plasma in patients with COPD. In patients undergoing routine diagnostic bronchoscopy and bronchoalveolar lavage those who were given $\boldsymbol{N}$-acetyl cysteine $(600 \mathrm{mg})$ thrice daily for five days had higher concentrations of cysteine in the plasma, but no significant differences in cysteine concentrations in bronchoalveolar lavage or epithelial lining fluid compared with a control group; nor were there any differences in reduced glutathione concentrations in plasma, bronchoalveolar lavage or epithelial lining fluids between the control and treated groups. Moreover, in patients under- going lung resection those treated with $\mathrm{N}$-acetyl cysteine (600 $\mathrm{mg}$ thrice daily for five days) had similar concentrations of cysteine and glutathione in both plasma and lung tissue when compared with a control untreated group.

Conclusions - These data suggest that, even when given in high oral doses, $\boldsymbol{N}$-acetyl cysteine does not produce a sustained increase in glutathione levels sufficient to increase the antioxidant capacity of the lungs.

(Thorax 1994;49:670-675)

There is increasing interest in the hypothesis that an imbalance between oxidants and antioxidants may be involved in the pathogenesis of emphysema. ${ }^{12}$ Oxidants such as reactive oxygen intermediates are produced by airspace phagocytes during lung inflammation or inhaled directly from the environment during cigarette smoking or as a result of air pollutants such as ozone. ${ }^{1-3}$ Such oxidants can damage lung connective tissue and epithelial cells directly by the process of lipid peroxidation. ${ }^{4}$ It has also been suggested that during cigarette smoking ${ }^{5}$ or ozone inhalation ${ }^{6}$ oxidants may reach and affect cells in the intravascular space. Moreover, a strong relation has been shown between a deficiency in the antioxidant capacity of plasma and the presence of a family history of lung disease. ${ }^{7}$ The plasma of patients with chronic obstructive pulmonary disease (COPD) has also been shown to have a reduced capacity to prevent elastolysis which may be compounded by an abnormal antioxidant capacity in the plasma of these patients. ${ }^{8}$ Thus, one therapeutic option in patients with COPD would be to increase the antioxidant capacity, not only of the plasma, but of the epithelial lining fluid and the lung cells in such patients.

$N$-acetyl cysteine is a drug which has been used for the past 20 years in the treatment of patients with COPD. ${ }^{9}$ Some long term studies have shown that oral administration of $N$ acetyl cysteine reduces the number of acute exacerbations in patients with chronic bronchitis, ${ }^{1011}$ although others have not. ${ }^{12}$ The doses of $\mathrm{N}$-acetyl cysteine used in these studies $^{10-12}$ were $200 \mathrm{mg}$ and $300 \mathrm{mg}$ twice daily, and $200 \mathrm{mg}$ thrice daily respectively. However, whether the efficacy of $N$-acetyl cysteine is mediated through its antioxidant action remains uncertain.

$N$-acetyl cysteine is rapidly metabolised
Dr W MacNee.

Received 7 January 1993 7 July 1993

Revised version received 8 February 1994

Accepted for publication

8 March 1994 
during absorption to cysteine, whose thiol group also possesses reducing and antioxidant properties. ${ }^{13}$ Moreover, cysteine is a precursor in the biosynthesis of glutathione, an important intracellular and extracellular antioxidant. ${ }^{1415}$ We have previously shown that $\mathrm{N}$-acetyl cysteine, $600 \mathrm{mg} /$ day for five days, can increase cysteine concentrations in plasma and temporarily increase the concentrations of glutathione in plasma and bronchoalveolar lavage fluid. ${ }^{16}$ This may have a therapeutic role by increasing the antioxidant capacity in the plasma and the lungs. However, because of the low bioavailability of $N$-acetyl cysteine, ${ }^{13}$ higher doses may be necessary to achieve a sustained effect within the airspaces or in lung tissue, particularly in patients with COPD.

The aim of this study was to compare the effects of two dose regimens of $N$-acetyl cysteine on plasma thiol concentrations in patients with COPD, and to study the effect of the higher dose regimen on thiol concentrations in bronchoalveolar lavage fluid and lung tissue.

\section{Methods}

EFFECTS OF $N$-ACETYL CYSTEINE ON PLASMA THIOL LEVELS IN NORMAL SUBJECTS AND PATIENTS WITH COPD

This study involved three groups: healthy, normal, non-smoking subjects (group 1) and two groups of patients, both ex-smokers, with COPD (groups 2 and 3 ) (table 1). The normal subjects were given $N$-acetyl cysteine by mouth one hour after meals in a single oral dose of $600 \mathrm{mg}$ daily for five days. Blood samples were withdrawn from an indwelling venous catheter at $0,0 \cdot 5,1 \cdot 0,1 \cdot 5,2 \cdot 0,4 \cdot 0,6 \cdot 0$, and 8.0 hours after $N$-acetyl cysteine on days 1 and 5. Based on these results, a comparison of plasma thiol levels was made in patients with COPD (group 2, table 1) at similar time points, excepting eight hours, following an oral dose of $600 \mathrm{mg} N$-acetyl cysteine which was preceded by treatment with $600 \mathrm{mg} N$-acetyl cysteine once daily for four days. Two blood samples separated by six hours were also withdrawn from both groups where no $N$-acetyl cysteine had been given in order to determine the stability of baseline concentrations of cysteine and glutathione.

In a further group of six patients with COPD (group 3, table 1) the effect on plasma thiol levels of a higher dosage of $N$-acetyl cysteine, $600 \mathrm{mg}$ thrice daily for five days, was assessed. Blood samples were withdrawn at $0,6,12$ and 24 hours - that is, at the time the $\mathrm{N}$-acetyl cysteine dose was due - on both day 1 and day 5 .

EFFECTS OF $N$-ACETYL CYSTEINE ON PLASMA AND BRONCHOALVEOLAR LAVAGE THIOL LEVELS Two groups (4 and 5, table 1 ) of patients who were either smokers or ex-smokers, all with peripheral bronchial carcinomas who were undergoing diagnostic bronchoscopy and bronchoalveolar lavage, were studied. Group 4 acted as a control group and were not given $N$ acetyl cysteine; subjects in group 5 were given $\mathrm{N}$-acetyl cysteine in a dose of $600 \mathrm{mg}$ thrice daily for five days. Blood and bronchoalveolar lavage samples (the latter from the lung without the tumour) were obtained from all patients. In the treated group bronchoalveolar lavage and blood samples were obtained three hours after the last dose of $N$-acetyl cysteine on day 5 of treatment.

EFFECT OF $N$-ACETYL CYSTEINE ON PLASMA AND LUNG THIOL LEVELS

Two groups of patients (groups 6 and 7, table 1), 22 in total, all with peripheral bronchial carcinomas planned for lung resection, were studied. Group 6 acted as a control group and were not given $\mathrm{N}$-acetyl cysteine; patients in group 7 were given $N$-acetyl cysteine $600 \mathrm{mg}$ thrice daily for 5 days before their operation. Samples were obtained 12-16 hours after the last dose of $N$-acetyl cysteine.

Informed consent was given by all subjects and patients, and the study had the approval of the local hospital ethical committee.

\section{METHODOLOGY}

Blood samples

Venous blood, $5 \mathrm{ml}$, was withdrawn into lithium heparin tubes and centrifuged at $4^{\circ} \mathrm{C}$ for 10 minutes at $800 \mathrm{~g}$ to obtain plasma.

\section{Measurement of urea}

The concentrations of urea in plasma and bronchoalveolar lavage fluid were measured using a standard kit (No 66, Sigma, Poole,

Table 1 Mean (SD) patient characteristics

\begin{tabular}{|c|c|c|c|c|c|}
\hline Group & Type & $n$ & Age (years) & $\begin{array}{l}F E V_{1} \\
\text { (\% predicted range) }\end{array}$ & $\begin{array}{l}\text { FVC } \\
\text { (\% predicted range) }\end{array}$ \\
\hline 1 & Normal subjects & $\begin{array}{l}6 \\
4 M: 2 F\end{array}$ & $30.0 \quad(8 \cdot 5)$ & $91-110$ & $93-114$ \\
\hline 2 & COPD & $\begin{array}{l}6 \\
4 \mathrm{M}: 2 \mathrm{~F}\end{array}$ & $69 \cdot 3(10 \cdot 6)$ & $26-50$ & $43-81$ \\
\hline 3 & COPD & $\begin{array}{l}6 \\
2 \mathrm{M}: 4 \mathrm{~F}\end{array}$ & $65 \cdot 5(4 \cdot 0)$ & $27-58$ & $28-68$ \\
\hline 4 & Bronchial carcinoma & $\begin{array}{l}6 \\
3 \mathrm{M}: 3 \mathrm{~F}\end{array}$ & $65 \cdot 2(11 \cdot 9)$ & $56-83$ & $65-80$ \\
\hline 5 & Bronchial carcinoma & $\begin{array}{l}6 \\
6 \mathrm{M}\end{array}$ & $71 \cdot 5 \quad(6 \cdot 1)$ & $49-74$ & $59-89$ \\
\hline 6 & Bronchial carcinoma & $\begin{array}{l}11 \\
7 \mathrm{M}: 4 \mathrm{~F}\end{array}$ & $62.9(10.4)$ & $59-100$ & 53-98 \\
\hline 7 & Bronchial carcinoma & $\begin{array}{l}11 \\
9 \mathrm{M}: 2 \mathrm{~F}\end{array}$ & $65 \cdot 2(6 \cdot 0)$ & $50-96$ & $62-90$ \\
\hline
\end{tabular}

$\mathrm{COPD}=$ chronic obstructive pulmonary disease; $\mathrm{FEV}_{1}=$ forced expiratory volume in one second; $\mathrm{FVC}=$ forced vital capacity. 
UK). Two volumes of the epithelial lining fluid were then calculated by the method of Rennard and coworkers. ${ }^{17}$

\section{Preparation of lung tissue}

Samples of lung tissue (2-10 g) were homogenised (Polytron, Kinematica, Switzerland) in trichloroacetic acid $(6.5 \% \mathrm{w} / \mathrm{v})$. The homogenates were centrifuged for 10 minutes at $1000 \mathrm{~g}$. The supernatants were neutralised with sodium hydrogen carbonate and assayed for thiols in the same way as for plasma samples $^{1618}$ (see below).

Thiol assay

The concentrations of cysteine, and $\mathrm{N}$-acetyl cysteine were determined by the method of Cotgreave and Moldeus, ${ }^{18}$ which we have previously validated. ${ }^{16}$ Briefly, immediately after centrifugation the samples (plasma, bronchoalveolar lavage fluid, or lung tissue supernatant) were treated with monobromobimane (Thiolyte, Calbiochem, Nottingham, UK) and the fluorescent thiol derivatives were separated using reverse phase, high pressure liquid chro-

Table 2 Mean (SE) plasma $N$-acetyl cysteine concentrations at 30 minute intervals for two hours after a single $600 \mathrm{mg}$ dose given before (day 1) and after (day 5) administration by mouth for five days $(600 \mathrm{mg} /$ day) to healthy volunteers (group 1 , $n=6)$ and on day 5 after administration to patients with chronic obstructive pulmonary disease (group 2, $n=6$ )

\begin{tabular}{|c|c|c|c|}
\hline \multirow{3}{*}{ Time after $N$-acetyl cysteine (hours) } & \multicolumn{3}{|c|}{ Concentration of $N$-acetyl cysteine ( $\mu$ mol/l) } \\
\hline & \multicolumn{2}{|l|}{ Group 1} & \multirow{2}{*}{$\begin{array}{l}\text { Group } 2 \\
\text { Day } 5\end{array}$} \\
\hline & Day 1 & Day 5 & \\
\hline $\begin{array}{l}0.0 \\
0.5 \\
1.0 \\
1.5 \\
2.0\end{array}$ & $\begin{array}{l}0 \\
1.8(0 \cdot 7) \\
1.5(0.9) \\
0 \cdot 1(0 \cdot 1) \\
0\end{array}$ & $\begin{array}{l}0 \\
1.8(0.8) \\
0.6(0.2) \\
0 \\
0\end{array}$ & $\begin{array}{l}0 \\
0 \cdot 6(0.3) \\
0 \cdot 6(0 \cdot 2) \\
0 \cdot 2(0 \cdot 1) \\
0\end{array}$ \\
\hline
\end{tabular}

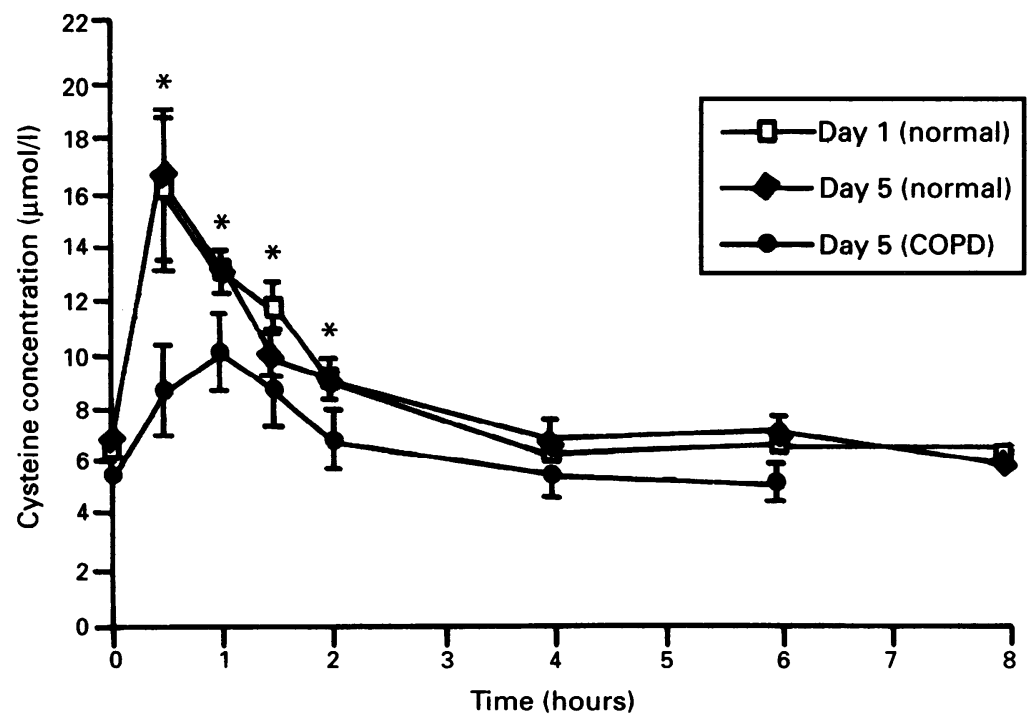

Figure 1 Plasma cysteine concentrations following a single oral dose (600 $\mathrm{mg})$ of $N$-acetyl cysteine before (day 1 ) and after $N$-acetyl cysteine $600 \mathrm{mg} /$ day was given by mouth for five days (day 5) to six normal subjects and six patients with COPD. Symbols represent mean values; bars indicate $S E .{ }^{*} p<0.05$ matography (Waters, Massachusetts, USA) and quantified using a fluorescence detector. ${ }^{18}$ Standard solutions of cysteine, glutathione, and $N$-acetyl cysteine were prepared daily with phosphate buffered saline ( $\mathrm{pH} 7 \cdot 4$ ) in the same way as the test samples. The limit of detection was 5 pmol. The coefficient of variation was $5 \%$ for repeated analyses. Tests for haemolysis were performed on plasma samples using diagnostics kit No 527 (Sigma, Poole, UK) and any samples with significant haemolysis were discarded.

\section{DATA ANALYSIS}

Areas under the plasma concentration-time curves were determined using the trapezoidal rule. ${ }^{19}$ Statistical analyses were performed on duplicate samples from which mean values were obtained. Analysis of variance and Wilcoxon rank sum were used on data to determine statistical significance.

\section{Results}

EFFECTS OF $N$-ACETYL CYSTEINE ON PLASMA THIOLS IN NORMAL SUBJECTS AND PATIENTS WITH COPD

When given by mouth in a dose of $600 \mathrm{mg}$ once daily $N$-acetyl cysteine was detected in the plasma of both healthy subjects (group 1) and patients with COPD (group 2) in low concentrations, reaching a maximum value 0.5 hours after $N$-acetyl cysteine was given, and was undetectable again by 2.0 hours (table 2 ). The maximum plasma $N$-acetyl cysteine concentrations tended to be lower in the patients with COPD than in the healthy subjects, but the difference was not significant.

Plasma cysteine concentrations increased significantly $(p<0.05)$ in healthy subjects on both days 1 and 5, and in patients with COPD on day 5 (fig 1), reaching a maximum 0.5 and 1.0 hour respectively after $600 \mathrm{mg}$ of $N$-acetyl cysteine. By 4.0 hours plasma cysteine levels had decreased to baseline values. Peak plasma cysteine concentrations tended to be lower in patients with COPD $[9.9(1.5) \mu \mathrm{mol} / \mathrm{l}]$ than in healthy subjects $[16.2(2.2) \mu \mathrm{mol} / 1]$ although this difference was not significant. In both groups the two control plasma levels of cysteine measured with an interval of six hours were similar to each other and to baseline levels measured before $N$-acetyl cysteine was given (data not shown).

The concentration of reduced glutathione in plasma increased variably in healthy subjects (fig 2) on days 1 and 5, reaching significance 6.0 hours after $N$-acetyl cysteine only on day 1. Although glutathione concentrations in plasma increased in all subjects, the maximum level was attained in individual subjects at different time points after $N$-acetyl cysteine was given on both days 1 and 5. Plasma reduced glutathione concentrations increased in four of the six patients with COPD on day 5 , 2.0 hours after $N$-acetyl cysteine (data not shown), but this increase did not reach statistical significance when compared with the baseline values. The areas under the plasma- 


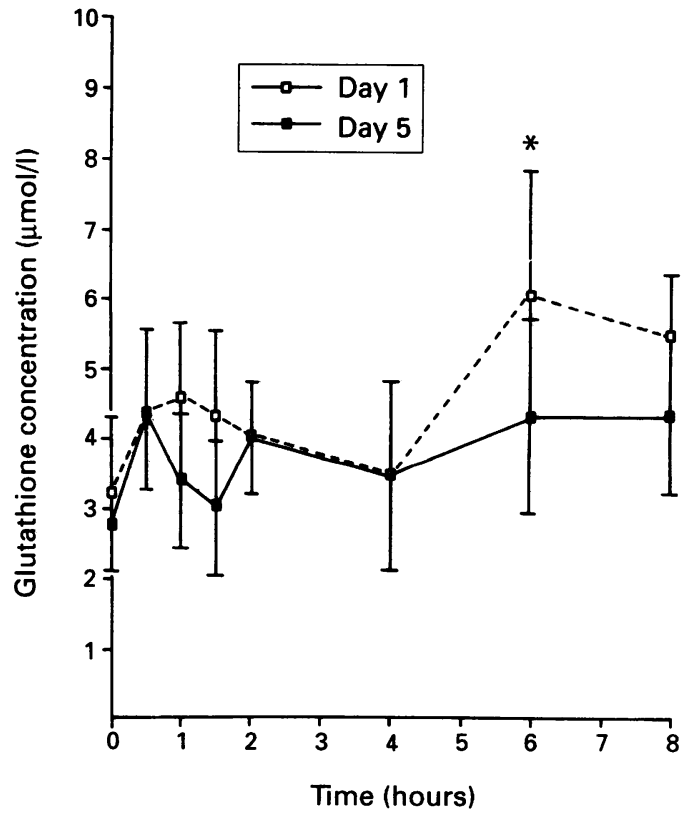

Figure 2 Plasma glutathione concentrations on day 1 and day 5 after $N$-acetyl cysteine $(600 \mathrm{mg} /$ day) was given by mouth to six healthy volunteers for five days. Symbols represent mean values; bars indicate $S E$ $* p<0.05$.

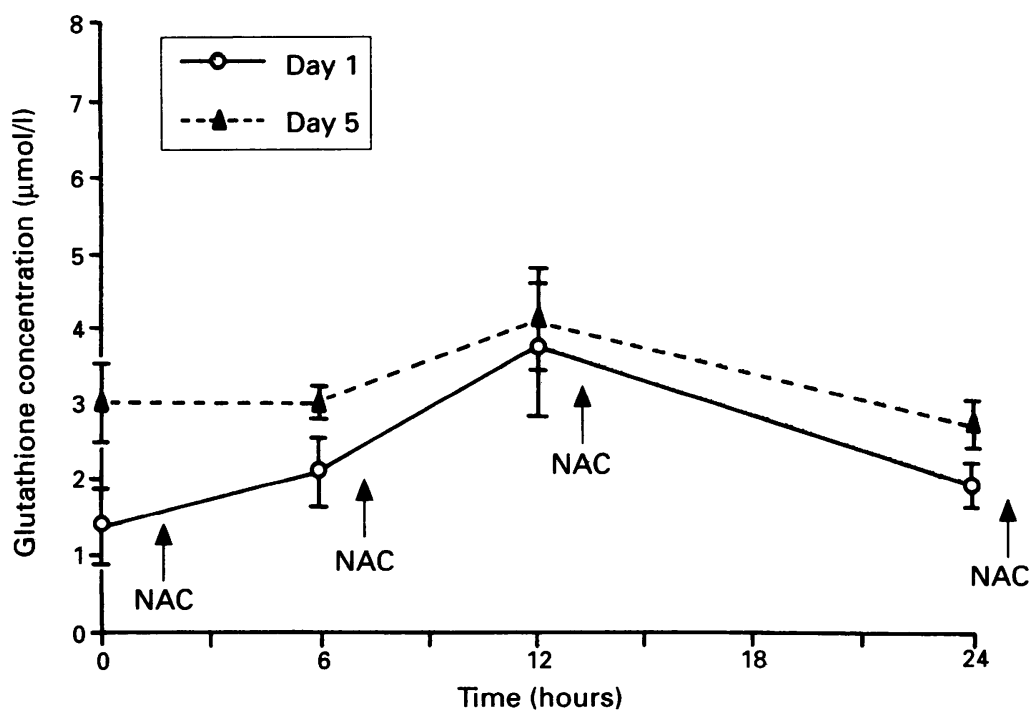

Figure 3 Plasma glutathione concentrations on day 1 and day 5 after $N$-acetyl cysteine (NAC) $600 \mathrm{mg}$ was given thrice daily to six patients with COPD. $N$-acetyl cysteine was given immediately after each blood sample was taken as indicated by the arrows. Symbols represent mean values; bars indicate $S E .{ }^{*} p<0.05$.

Table 3 Mean (SE) epithelial lining fluid (ELF) volumes and the concentrations of cysteine, glutathione (GSH), and urea in the plasma, bronchoalveolar lavage fluid $(B A L F)$, and ELF in two groups of patients undergoing routine diagnostic bronchoscopy: a control group and a group treated with $N$-acetyl cysteine $600 \mathrm{mg}$ thrice daily for five days

\begin{tabular}{|c|c|c|}
\hline & Control (group 4) & $N$-acetyl cysteine (group 5) \\
\hline $\begin{array}{l}\text { ELF volume }(\mathrm{ml}) \\
\text { Plasma cysteine }(\mu \mathrm{mol} / \mathrm{l}) \\
\text { Plasma GSH }(\mu \mathrm{mol} / \mathrm{l}) \\
\text { BALF cysteine }(\mu \mathrm{mol} / \mathrm{l}) \\
\text { BALF GSH }(\mu \mathrm{mol} / \mathrm{l}) \\
\text { ELF cysteine }(\mu \mathrm{mol} / \mathrm{l}) \\
\text { ELF GSH }(\mu \mathrm{mol} / \mathrm{l}) \\
\text { Plasma urea }(\mathrm{mg} / 100 \mathrm{ml}) \\
\text { BALF urea }(\mathrm{mg} / 100 \mathrm{ml})\end{array}$ & $\begin{array}{cc}2.1 & (0.5) \\
3.5 & (0.8) \\
7.0 & (1.8) \\
0.1 & (0.1) \\
2.4 & (0.9) \\
2.9(1.3) \\
114.0(44.5) \\
8.2(1.3) \\
0.17(0.04)\end{array}$ & $\begin{aligned} 2.0 & (0.6) \\
8.4 & (1.1)^{*} \\
3.6 & (0.8) \\
0.5 & (0.4) \\
2.9 & (0.6) \\
25.0 & (18.6) \\
137.0 & (22.0) \\
10.8 & (0.7) \\
0.22 & (0.04)\end{aligned}$ \\
\hline
\end{tabular}

concentration time curves for cysteine (group $1,52.0(2 \cdot 3) \mu \mathrm{mol} / 1$; group $2,39 \cdot 0(4 \cdot 9) \mu \mathrm{mol} / \mathrm{l})$ and glutathione (group 1, 21.7 $(3.3 \mu \mathrm{mol} / \mathrm{l}$, group $2,16 \cdot 8(1 \cdot 7) \mu \mathrm{mol} / \mathrm{l})$ up to six hours after $N$-acetyl cysteine $600 \mathrm{mg}$ daily on day 5 were not significantly different between normal subjects and patients with COPD. In patients with COPD who were given the higher dose of $N$ acetyl cysteine $(600 \mathrm{mg}$ thrice daily for five days, group 3), $N$-acetyl cysteine was not detected in any of the plasma samples on either days 1 or 5 at the times when blood was sampled, nor was there any increase in plasma cysteine concentrations. After $\mathrm{N}$-acetyl cysteine on days 1 and 5 glutathione concentrations in plasma tended to increase on day 1 , but this change was not significant (fig 3 ). By day 5, however, reduced glutathione concentrations in plasma had significantly increased $(p<0.05)$ at 12 hours, immediately before the last dose of $N$-acetyl cysteine, compared with the levels before $N$-acetyl cysteine was given on day 1 (fig 3).

EFFECTS OF $N$-ACETYL CYSTEINE ON PLASMA AND BRONCHOALVEOLAR LAVAGE THIOL LEVELS When $600 \mathrm{mg} N$-acetyl cysteine was given thrice daily for five days to patients undergoing routine diagnostic bronchoscopy and bronchoalveolar lavage (group 5) cysteine concentrations were significantly higher $(p<0.01)$ in plasma, but not in bronchoalveolar lavage or epithelial lining fluids, than the control group (group 4) (table 3). Glutathione concentrations in plasma, bronchoalveolar lavage, and epithelial lining fluids were not significantly different between the control and $\mathrm{N}$-acetyl cysteinetreated groups. Moreover, epithelial lining fluid volumes and urea concentrations in plasma and bronchoalveolar lavage fluid were similar in the control group and those treated with $N$-acetyl cysteine.

EFFECTS OF $N$-ACETYL CYSTEINE ON PLASMA AND LUNG THIOL LEVELS

When $600 \mathrm{mg} N$-acetyl cysteine was given thrice daily for five days to patients undergoing pneumonectomy (group 7) there was no significant difference in cysteine and glutathione concentrations in either plasma or lung tissue compared with the control group (group 6), although cysteine and glutathione levels were higher in all patients receiving $N$-acetyl cysteine $(\mathrm{p}<0.1$, table 4$)$. $N$-acetyl cysteine was not detected in any of the samples in these studies.

\section{Discussion}

Intervention in patients with COPD to enhance the antioxidant capacity of plasma or the epithelial lining fluid is a research area of increasing interest. ${ }^{20}$ The potential for $\mathrm{N}$-acetyl cysteine to act directly as an antioxidant is limited by its low bioavailability, which has been calculated to be between $4 \%$ and $10 \% .^{21-24}$ Cysteine released by deacetylation of $\mathrm{N}$-acetyl cysteine $\mathrm{e}^{25-27}$ is itself an antioxidant, ${ }^{13}$ 
Table 4 Mean (SE) concentrations of cysteine and glutathione (GSH) in the plasma and lung tissue of two groups of patients undergoing pneumonectomy: a non-treated control group and a group treated with $N$-acetyl cysteine $600 \mathrm{mg}$ thrice daily for five days

\begin{tabular}{lcc}
\hline & Control (group 6) & N-acetyl cysteine (group 7) \\
\hline Plasma $(\mu \mathrm{mol} / \mathrm{l})$ & $9.0(0.7)$ & $9.4(2.3)$ \\
Cysteine & $5.2(1 \cdot 1)$ & $5.0(1.3)$ \\
GSH & & \\
Lung tissue (nmol/g lung) & $19.1(8.5)$ & $30.3(11.8)$ \\
Cysteine & $119.7(27.5)$ & $178.1(41.9)$ \\
GSH & & \\
\hline
\end{tabular}

however, and a precursor of glutathione, an important antioxidant in cells and extracellular fluids. ${ }^{14-15}$ In a previous study we suggested that it may be possible to enhance the levels of glutathione in plasma and bronchoalveolar lavage fluid. ${ }^{16}$ We have extended these data in this study by comparing thiol concentrations following administration of $\mathrm{N}$-acetyl cysteine in normal subjects and patients with COPD in the latter following a higher dosage regimen than in our previous study. ${ }^{16}$ We have also measured thiol concentrations in both epithelial lining fluid and in lung tissue. When given in the lower dose regimen $(600 \mathrm{mg} /$ day for 5 days) $N$-acetyl cysteine was detected in low concentrations (table 2) in the plasma of both normal subjects and patients with COPD for up to 2.0 hours after its administration. This agrees with other published data ${ }^{2128}$ which indicate that $\mathrm{N}$-acetyl cysteine disappears rapidly from the plasma when given by mouth. There was no accumulation of $N$-acetyl cysteine as the concentrations in the plasma of normal subjects on day 5 , prior to dosing with the drug, were similar to those on day 1 . Cotgreave et $a l^{27}$ also reported little or no accumulation of $\mathrm{N}$-acetyl cysteine in normal subjects following repeated dosing.

No $\mathrm{N}$-acetyl cysteine was detected in the plasma, bronchoalveolar lavage fluid, epithelial lining fluid, or lung tissue of patients undergoing diagnostic bronchoscopy and bronchoalveolar lavage, or in those undergoing pneumonectomy, which can be explained by the fact that blood sampling was undertaken three and 12-16 hours after $N$-acetyl cysteine, respectively.

Peak plasma cysteine concentrations in normal subjects occurred 0.5 hours after a single $600 \mathrm{mg}$ dose of $\mathrm{N}$-acetyl cysteine was given, declining to baseline concentrations by $4 \cdot 0$ hours (fig 1) with no evidence of a cumulative effect after five days of treatment.

Cysteine is a precursor in the biosynthesis of glutathione. ${ }^{29}$ Increased glutathione concentrations in plasma in normal subjects (fig 2) occurred at variable times after $N$-acetyl cysteine. As with $N$-acetyl cysteine and cysteine concentrations, there was no cumulative effect on the levels of glutathione in plasma after five days of treatment with $\mathrm{N}$-acetyl cysteine in normal subjects, nor was there a significant change in the plasma glutathione concentrations in patients with COPD, using this dosage regimen.
There was a trend for the areas under the plasma concentration-time curves for cysteine and glutathione to be lower in patients with COPD than in normal subjects, which may represent altered metabolism of the drug in such patients. ${ }^{30}$ Hypoxia, although mild in the patients in this study, has been shown experimentally to depress protein synthesis in man, ${ }^{31}$ and may inhibit or delay gastric emptying leading to malabsorption. In order to produce the same increase in antioxidant status in patients with COPD as in normal subjects it may be necessary to increase the dose of $N$ acetyl cysteine to compensate for this apparent malabsorption.

This hypothesis is supported by the results obtained when $N$-acetyl cysteine was given in the higher dosage of $600 \mathrm{mg}$ thrice daily for five days to another group of patients with COPD. In this case, as the first blood sample was taken six hours after $N$-acetyl cysteine, plasma cysteine and glutathione concentrations did not increase significantly on day 1 since the time of blood sampling would miss the transient increase in plasma cysteine and glutathione levels.

After five days of treatment with $N$-acetyl cysteine in a dose of $600 \mathrm{mg}$ thrice daily there was a significant increase in plasma levels of glutathione (fig 3). These data indicate that it is possible to produce a small but sustained increase in glutathione levels in plasma following treatment with $N$-acetyl cysteine in patients with COPD, but only by multiple high dosing.

Two studies in patients with chronic bronchitis with well preserved lung function have shown that $N$-acetyl cysteine, in dosage regimens of $200 \mathrm{mg}$ and $300 \mathrm{mg}$ twice daily respectively, reduced the number of acute exacerbations of bronchitis. ${ }^{1011}$ However, a regimen of $200 \mathrm{mg}$ thrice daily in more disabled patients showed no effect. ${ }^{12}$ This may be explained by poorer absorption of the drug in the patients with the more severe disease producing lower plasma levels. It is difficult to conclude, however, that the modest increase in glutathione levels or the transient increase in plasma cysteine levels and the consequent increase in plasma antioxidant potential shown in the present study could account for the reduction in exacerbations of COPD in patients treated with $N$-acetyl cysteine. Increasing the antioxidant levels in lung tissue or epithelial lining fluid, however, may be more important in protecting the lungs from oxidant-induced injury than enhancing plasma concentrations. $\mathrm{N}$-acetyl cysteine in a higher dosage than in our previous study ${ }^{16}$ did increase plasma cysteine concentrations significantly (table 3), indicating that $\mathrm{N}$-acetyl cysteine had been absorbed. There was no corresponding increase in glutathione concentrations in plasma, however, at least at the times when blood samples were withdrawn, nor in cysteine and glutathione concentrations in bronchoalveolar lavage, epithelial lining fluid, or lung tissue. We may have missed any changes in thiol concentrations following $N$ acetyl cysteine because of the limited time 
points at which samples were obtained. However, these time points were chosen to determine if treatment with $N$-acetyl cysteine in the maximum tolerated oral dose could produce a sustained rise in thiol levels in plasma or epithelial lining fluid. This is likely to be more important therapeutically than the transient increases in cysteine and glutathione which we have shown in this and our previous study. ${ }^{16}$ This study has clearly indicated that this aim is not achievable.

In summary, our results suggest that $N$ acetyl cysteine may not be the drug of choice to enhance the glutathione antioxidant potential of the lungs, particularly in patients with COPD where absorption may be poor. The results of these studies do not suggest that a sustained increase in cysteine or glutathione in plasma, epithelial lining fluid, or lung tissue can account for the effect of this drug upon acute exacerbations in patients with COPD. The development of drugs which can enhance glutathione levels but have better bioavailability than $N$-acetyl cysteine could improve our ability to augment the antioxidant potential of the lungs. Alternatively, thiol drugs which are not metabolised but are themselves antioxidants would allow us to test the hypothesis that enhancing the antioxidant status in patients with COPD could prevent clinical deterioration.

Our thanks go to Dr R Sankaran and Dr K Donaldson for help with this study. The work was supported by the Norman Salvesen Emphysema Research Trust.

1 Flenley DC, Downing I, Greening AP. The pathogenesis of emphysema. Bull Eur Physiopathol Respir 1986;22:2455525.

2 Riley DJ, Kerr JS. Oxidant injury of the extracellular matrix - potential role in the pathogenesis of pulmonary emphysema. Lung 1985;163:1-13.

3 Johnson KJ, Fantone JC, Kaplan J, Ward PA. In vivo damage of rat lungs of oxygen metabolites. $\mathcal{f}$ Clin Invest 1981;67:983-93.

4 Henson PM, Johnston RB. Tissue injury in inflammation: oxidants, proteinases and cationic proteins. $\mathcal{F}$ Clin Invest 1987;79:669-74.

5 Weitz JI, Crawley KA, Lamnan SL, Lippman VI, Yu J. Increased neutrophil elastase activity in cigarette smokers. Ann Intern Med 1987;107:680-2. in cigarette

6 Buckley RD, Hackney JD, Clark K, Posin C. Ozone and human blood. Arch Environ Health 1975;30:40-3.

7 Taylor JC, Madison R, Kosinska D. Is antioxidant deficiency related to chronic obstructive pulmonary disease? Am Rev Respir Dis 1986;134:285-9.

8 Martin WJ, Taylor JC. Abnormal interaction of alpha-1antitrypsin and leucocyte elastolytic activity in patients with chronic obstructive pulmonary disease. Am Rev Respir Dis 1979;120:411-9.

9 Ziment I. Acetylcysteine: a drug with an interesting past and a fascinating future. Respiration 1986;50:26-30.
10 Boman G, Backer U, Larsson S, Melander B, Wahlander L. Oral acetylcysteine reduces exacerbation rate in chronic bronchitis. Eur $\mathcal{F}$ Respir Dis 1983;64:405-15.

11 Rasmussen JB, Glennow C. Reduction in days of illness after long term treatment with $N$-acetyl cysteine controlled-release tablets in patients with chronic bronchitis. Eur $\mathcal{F}$ Respir Dis 1988;1:351-5.

12 British Thoracic Society Research Committee. Oral $N$ acetyl cysteine and exacerbation rates in patients with chronic bronchitis and severe airways obstruction. Thorax 1985;40:832-5.

13 Bonanomi L, Gazzaniga A. Toxicological, pharmacokinetic and metabolic studies on acetyl cysteine. Eur $\mathcal{f}$ Respir Dis 1980;61:52-8.

14 Tsan M-F, Danis EH, Del Vecchio PJ, Rosano CL. Enhancement of intracellular glutathione protects endothelial cells against oxidant damge. Biochem Biophys Res Commun 1985;127:270-6.

15 Berggren M, Dawson J, Moldeus P. Glutathione biosynthesis in the isolated perfused rat lung: utilisation of thesis in the isolated perfused rat lung: utilisation of

16 Bridgeman MME, Marsden M, MacNee W, Flenley DC, Ryle AP. Cysteine and glutathione levels in plasma and bronchoalveolar lavage fluid after treatment with $N$-acetyl cysteine. Thorax 1991;46:39-42.

17 Rennard SI, Basset G, Lecossier D, O'Donnell KM, Pinkston P, Martin PG, et al. Estimation of epithelial lining fluid recovered by lavage using urea as a marker of dilution. f Appl Physiol 1986;60:532-8.

18 Cotgreave IA, Moldeus P. Methodologies for the application of monobromobimane to the simultaneous analysis of soluble and protein components of biological systems. f Biochem Biophys Methods 1986;13:231-49.

19 Gibaldi M, Perrier D. Pharmacokinetics. New York: Marcel Dekker, 1982.

20 Heffner JE, Repine JE. Pulmonary strategies of antioxidant defense. Am Rev Respir Dis 1989;140:531-54.

21 Olsson B, Johansson M, Gabrielson J, Bolme P. Pharmacokinetics of reduced and oxidised $N$-acetyl cysteine. Eur $\mathfrak{J}$ Clin Pharmacol 1988;34:77-82.

22 Borgstrom L, Kagedal B, Paulsen O. Pharmacokinetics of $N$-acetyl cysteine in man. Eur $f$ Clin Pharmacol 1986;31:217-22.

23 Cotgreave IA, Moldeus P. Methodologies for the analysis of reduced and oxidised $N$-acetyl cysteine in biological systems using monobromobimane. Biopharm Drug Dispos 1987;8:365-75.

24 Burgunder JM, Varriale A, Lauterburg BH. Effect of $N$ acetyl cysteine on plasma cysteine and glutathione following paracetamol administration. Eur $\mathcal{f}$ Clin Pharmacol ing paracetamol

25 Cotgreave IA, Berggren M, Jones TW, Dawson J, Moldeus $P$. Gastrointestinal metabolism of $N$-acetyl cysteine in the $\mathrm{P}$. Gastrointestinal metabolism of $N$-acetyl cysteine in the
rat, including an assay for sulfite in biological systems. rat, including an assay for sulfite in biol
Biopharm Drug Dispos 1987;8:377-86.

26 Sheffner AL, Medler EM, Bailey KR, Gallo DG, Mueller AJ, Sarett HP. Metabolic studies with $N$-acetyl cysteine. Biochem Pharmacol 1966;15:1523-35.

27 Cotgreave IA, Eklund A, Larsson K, Moldeus P. No penetration of orally administered $\mathrm{N}$-acetyl cysteine into the bronchoalveolar lavage fluid. Eur $\mathcal{f}$ Respir Dis 1987;70:73-7.

28 Kagedal B, Kallberg M, Martensson J. Determination of non-protein bound $\mathrm{N}$-acetyl cysteine in plasma by high performance liquid chromatography. $\mathfrak{f}$ Chromatogr 1984;311:170-7.

29 Richman PG, Meister A. Regulation of $\gamma$-glutamyl cysteine synthetase by non-allosteric inhibition by glutathione. synthetase by non-allosteric

30 Morrison WL, Gibson JNA, Scrimgeour C, Rennie MJ. Muscle wasting in emphysema. Clin Sci 1988;75:415-20.

31 Rennie MJ, Babij P, Sutton JR, Tonkins WJ, Read WW, Ford $\mathrm{C}$, et al. Effects of acute hypoxia on forearm leucine metabolism. In: Sutton JR, Houston CS, Jones NL, eds. Hypoxia, exercise and altitude: Proceedings of the Third Banff International $H$ 